\title{
Parenting experiences of mothers living with a chronic mental illness
}

\author{
Angelina Motlalepula Rampou ${ }^{a, 1}$, Yolanda Havenga ${ }^{a, b, *}$, Mary Madumo ${ }^{a}$ \\ a Department of Nursing Science, Sefako Makgatho Health Sciences University, PO Box 200, MEDUNSA, 0204, \\ South Africa \\ ${ }^{\mathrm{b}}$ Tshwane University of Technology and Adelaide Tambo School of Nursing Science, Private Bag P X680, Pretoria, \\ South Africa
}

\section{A R T I C L E I N F O}

Article history:

Received 7 February 2015

Accepted 28 April 2015

Available online 1 October 2015

\section{Keywords:}

Chronic mental illness

Experiences

Mother

Parenting

Parent accompaniment programme

\begin{abstract}
A B S T R A C T
Background: Intrapersonal, interpersonal, social and economic factors associated with chronic mental illness influence mothers' parenting abilities which in turn influence childhood mental health.

Aim: The aim of the study was to explore and describe the parenting experiences of mothers with a chronic mental illness.

Methods: An explorative, descriptive and qualitative research design was used. Ten participants were purposively sampled until saturation occurred. Data was collected using indepth individual interviews and a content analysis was carried out.

Results: Mothers with a chronic mental illness experienced various challenges and expressed their family support needs.

Conclusion: A family-centred approach to mental healthcare, treatment and rehabilitation is proposed.

Copyright () 2015, The Authors. Production and hosting by Elsevier B.V. on behalf of Johannesburg University. This is an open access article under the CC BY-NC-ND license

(http://creativecommons.org/licenses/by-nc-nd/4.0/).
\end{abstract}

\section{Introduction}

Mental illness impacts on mothers' parenting skills and abilities and influences the whole family (Maybery \& Reupert, 2009, p. 784). However, being a mother goes beyond the signs and symptoms of mental illnesses (Montgomery, Tompkins, Forchuk, \& French, 2006, p. 26).
Various intrapersonal, interpersonal, social and economic factors associated with mental illness influence mothers' parenting abilities, which could pose a risk to the wellbeing of their children. However, supportive familycentred interventions for mothers with a chronic mental illness have the potential to reduce risk and prevent negative outcomes for mothers as well as their children (Craig, 2004, p. 925).

\footnotetext{
* Corresponding author. Tshwane University of Technology, this in a Nursing School in Tshwane University of Technology Adelaide Tambo School of Nursing Science, Private Bag P X680 Pretoria, South Africa. Tel.: +27 123824280.

E-mail addresses: angyr@vodamail.co.za (A.M. Rampou), havengay@tut.ac.za (Y. Havenga), mary.madumo@smu.ac.za (M. Madumo).

1 Tel.: +2782561 0229 .

Peer review under responsibility of Johannesburg University. http://dx.doi.org/10.1016/j.hsag.2015.04.004

1025-9848/Copyright () 2015, The Authors. Production and hosting by Elsevier B.V. on behalf of Johannesburg University. This is an open access article under the CC BY-NC-ND license (http://creativecommons.org/licenses/by-nc-nd/4.0/).
} 


\subsection{Background}

Parenting is the process of raising and educating a child from birth until adulthood that involves endeavouring to realise the physical, emotional, psychological, and developmental needs of a child (David, Styron, \& Davidson, 2011, pp. 143-144). Moreover, parenting is a long-term commitment requiring physical and practical tasks and psychological responsibilities such as providing affection, stimulation and effective discipline (David et al., 2011, p. 145; Ward \& Wessels, 2013, p. 62). In addition, through all stages of development, effective parenting is characterised by consistence, warmth, responsiveness, nurturance, structure, developmentally-appropriate supervision and autonomy (Eshel, Daelmans, de Mello, \& Martines, 2006, p. 995; Oyserman, Mowbray, Meares, \& Firminger, 2000 p. 296; Ward \& Wessels, 2013, p. 62). Responsive parenting is evidenced by prompt, contingent and appropriate interaction between parent and child. This form of parenting enhances growth and physical development, and is associated with better outcomes for children (Eshel et al., 2006).

Internationally, epidemiological studies indicate that the prevalence of mental illness is similar for men and women. However, depression and anxiety disorders affect more women than men (Doucet, Letourneau, \& Stoppard, 2010, pp. 297-298; Moultrie \& Kleintjies, 2006, p. 351). Various roles in society contribute to psychological pressure on women that have an influence on their mental health. For example, women are often expected to take primary responsibility for all the needs of their children and other family members, even if they are employed full-time (Doucet et al., 2010, p. 298).

Many women with a chronic mental illness are mothers as they have normal fertility rates and bear an average number of children (Kahng, Oyserman, Bybee, \& Mowbray, 2008, p. 162). It has also been found that severely mentally ill women are more likely than men to be parents (Diaz-Caneja \& Johnson, 2004, p. 472). Maybery, Reupert, Patrick, Goodyear, and Crase (2009, p. 22) report that $23.3 \%$ of children in Australia have a parent with a mental illness that is not related to substance abuse. In the United Kingdom, it has been found that $10-15 \%$ of children live with a parent with a mental illness (Falkov \& Lindsey, 2011, p. 6). Although similar figures for South Africa could not be found, it is plausible to assume that many people with serious and chronic mental illnesses in South Africa, too, are parents (Oyserman et al., 2000).

Parenting is accompanied by challenges and opportunities. This is no different for mothers with a chronic mental illness. They do, however, have additional challenges related to their mental health and the associated influence on their intrapersonal resources, coping ability, interpersonal relationships and social and economic levels of function that lead to substantial additional stress for them (Craig, 2004, p. 924; Jessop \& De Bondt, 2012, p. 150; Reupert \& Maybery, 2011, p. 257). Serious and chronic mental illness thus has the potential to influence responsive parenting and affects functioning on a physical, psychological, social, occupational and interpersonal level (Sadock \& Sadock, 2007, p. 467; World Health Organization, 2001). Serious mental illness is associated with difficulty in parenting, including elevated parenting stress and dampened nurturance and inappropriate affective responses (Maybery \& Reupert, 2009, p. 784). It is therefore reasonable to assume that children of mothers with mental illness are an at-risk group (Craig, 2004). However, not all mothers and their children are affected by mental illness in the same manner.

The risk to the children of mothers with a mental illness is a multifaceted interaction between multiple factors. The onset and timing of the mental illness, the children's developmental age and sociocultural factors influence the risk to children (Oyserman et al., 2000, p. 296). Some mothers develop a mental illness before they have children; others following the change to parenthood. Some have single episodes and others have chronic relapsing disorders (Craig, 2004, p. 924). A mother with a serious and chronic mental illness might have more than one episode of illness, meaning that the child is exposed during more than one developmental phase (Oyserman et al., 2000, p. 296). Often, mothers are hospitalised during acute periods of illness or are separated from their children. In certain circumstances, when there is a concern for the child's safety, a mother might be unable to continue as the primary caregiver (Jessop \& De Bondt, 2012, p. 152) and the child might have to be separated from her. It should, however, also be appreciated that separation between the mother and child over an extended period could have negative consequences for them both (David et al., 2011, p. 142).

It is not clear whether certain mental disorders impact on parenting abilities more than others. So-called "severe mental illnesses" such as bipolar disorder and schizophrenia have been reported to impact on parent-child attachment; however, the severity and chronicity of the disorder are possibly more significant than the type of disorder. The effect of a specific diagnosis on parenting practices and relational insufficiencies increase the risk to children (Ackerson, 2003, p. 190; Craig, 2004, p. 924).

The mothers' mental illnesses themselves are not the only risk to their children. Associated challenges relate to family disruptions and conflicts, being a single parent, social isolation, limited social support, stigmatisation, financial stressors and related problems of poverty (Diaz-Caneja \& Johnson, 2004, p. 476; Jessop \& De Bondt, 2012, p. 53; Oyserman et al., 2000, p. 311; Seeman, 2008, p. 335). Moreover, compared with women without a mental illness, women with a serious mental illness have more sexual partners, sexual assaults and unplanned pregnancies (Montgomery et al., 2006, p. 21).

\subsection{Problem statement}

The presence of a serious and chronic mental illness and implications associated with it threaten mothers' ability to parent (Montgomery et al., 2006, p. 26). Their children are an at-risk group (Craig, 2004, p. 924). These children may experience mental health problems (Craig, 2004, p. 925) and delays in their physical, social and emotional development (Craig, 2004, p. 924; Lagan, Knights, Barton, \& Boyce, 2009, p. 55; Seeman, 2008, p. 334). However, interventions that support atrisk children and their mothers may reduce the risk to these children (Beardslee, Wright, Gladstone, \& Forbes, 2007, p. 709). 
Currently, mental health services do not adequately support these mothers or intervene (Seeman, 2008, p. 335), and their parenting concerns are greatly neglected (Nicholson, Geller, Fisher, \& Dion, 1993, p. 484). There is thus limited focus by mental health services on these mothers' parenting roles, and questions about parenting are not routinely included in the assessment and management of mothers with a serious and chronic mental illness (Diaz-Caneja \& Johnson, 2004, p. 477; Dipple, Smith, Andrews, \& Evans, 2002, p. 339). In addition, mothers often withhold information from healthcare providers when discussing their parenting challenges and needs, as they fear being separated from or losing custody of their children (David et al., 2011, p. 145; Diaz-Caneja \&Johnson, 2004, p. 472; Thomson \& Fudge, 2005, p. iii). Their concerns about being separated are not unfounded, as separation and custody loss are frequent among women with severe mental illness (Diaz-Caneja \& Johnson, 2004, p. 472; Dipple et al., 2002, p. 339).

Maybery and Reupert (2009, pp. 786-787) report that the barriers that hinder health services' capacity to respond to children and families where a parent has a severe mental illness can be found in the lack of policy and consistent guidelines to identify the parenting status of mental healthcare users, inadequate resource allocation and managers' non-support of family-focused interventions. Healthcare providers perceive their roles to be limited to caring for the adult patients and not their families, and they often have limited skills and knowledge in working with families (DiazCaneja \& Johnson, 2004, p. 480-481). Finally, few empirically tested and relevant programmes exist to support mothers with serious mental illnesses (Craig, 2004, pp. 923; 927; David et al., 2011, p. 138; Montgomery et al., 2006, p. 21).

Support for mothers should be informed by their contextspecific challenges and parenting needs, which have until now received little research attention to inform service provision (Australian Infant Child Adolescent and Family Mental Health Association, 2004, p. 7; Dipple et al., 2002, p. 337; Diaz-Caneja \& Johnson, 2004, p. 473). Mothers' experiences that would inform mental healthcare services on how to support them should therefore be explored (David et al., 2011, p. 144; Oyserman et al., 2000 , p. 311). Contextually relevant empirical evidence to inform this support was required in this specific setting and led to the research question: "What are the parenting experiences of mothers with chronic mental illness seen at a Gauteng Hospital?"

\subsection{Aim and objective}

The aim of the study was to support mothers with chronic mental illness. In order to inform the support, the objective of the study was to explore and describe the parenting experiences of mothers with a chronic mental illness.

\subsection{Theoretical framework}

The theory for health promotion in nursing (University of Johannesburg, Department of Nursing Science, 2009, p. 4) formed the theoretical framework of this study. This theory promotes the health of the individual, family, group and community. In this study, we looked at the promotion of the mental health of mothers with a chronic mental illness in order to assist them to cope more effectively with parenting.

\section{Research method and design}

\subsection{Design}

The research design was an explorative, descriptive and qualitative research design. Qualitative health-related research focuses on the experiences of persons with regard to their illness, health, caregiving and the cultural perceptions related to health and illness (Morse, 2011, p. 403). The objective of this study was to describe what mothers experience with regard to parenting while chronically mentally ill, as well as how they interpret the experiences and the meanings the experiences hold for them (Brink, Van Der Walt, \& Van Rensburg, 2006, p. 113). In attempting to describe the experience, the researcher focused on what was happening in the lives (Brink et al., 2006, p. 113) of the mothers and what was important about their parenting experiences.

\subsection{Setting}

The study was conducted in Tshwane, an area north of Gauteng, at a general hospital with two psychiatric wards and an outpatient department. Services at the outpatient department are provided to mental healthcare users from Mondays to Fridays.

\subsection{Population and sampling}

The accessible population (Burns \& Grove, 2009, pp. 343-344; Polit \& Beck, 2012, p. 274) consisted of all mothers who accessed outpatient mental healthcare, treatment and rehabilitation at a Gauteng hospital. This study utilised purposive sampling (Brink et al., 2006, p. 133). Ten mothers (who gave birth to their children) with a chronic mental illness, 18 years and older, diagnosed, in contact with reality, living at home, and willing to participate were included.

In this study, chronic mental illness in mothers refers to a mother diagnosed with major depressive disorder, schizophrenia or bipolar mood disorder (American Psychiatric Association, 2013), and having received care, treatment and rehabilitation for more than six months. All mothers with a dual diagnosis of a substance-related or personality disorder were excluded. The rationale for excluding mothers with a dual diagnosis including a substance-related disorder was that substance use and abuse have patterns impacting on the parenting abilities of mothers, and the researcher's focus in this study was on chronic mental illness. The sample size was determined by saturation, evidenced by repetition of themes (Burns \& Grove, 2009, p. 361) and confirmed by the researcher, supervisors and independent coder.

\subsection{Data collection methods}

The data was collected over a period of six months in 2012 and 2013 by means of in-depth individual interviews (Greeff, 2011, p. 348). This allowed the participants to share their experiences of parenting with a chronic mental illness in an open manner.

Before data collection commenced, the interview schedule was piloted with six participants to ensure that the questions elicited the required information and that the researcher's 
interviewing technique was non-leading, and to ensure that the questions were clear and would stimulate rich information sharing from participants (Brink et al., 2006, p. 143). The questions were adapted after piloting, and only the last of the six interviews was included in the data, as it adequately generated appropriate data. The data from the other five interviews was discarded.

Biographical information obtained before the interviews included the participants' age, marital or relationship status, level of education, employment status, diagnosis and number of children. The interviews commenced with the following open-ended central question: "Tell me about your experiences of being a mother." This question allowed the participants to respond in their own words and describe their experiences.

The in-depth individual interviews were conducted by the researcher in Setswana, the participants' mother tongue, in the psychiatric outpatient department of the Gauteng hospital. Probing was used to obtain clarity and to enable the mothers to elaborate more. Interviews were audio-recorded; descriptive and reflective field notes were kept (Holloway \& Wheeler, 2010, p. 96).

\subsection{Data analysis}

The researcher prepared the interviews for analysis by transcribing the audio-recordings verbatim in Setswana, and translating these into English. Field notes were added to the transcripts. The independent coder, who was also Setswanaspeaking, checked the translated transcripts for accuracy. The researcher and the independent coder independently analysed the transcripts using Tesch's descriptive method (Creswell, 2009, p. 186) by reading all the transcripts carefully to get a sense of what the mothers were saying. Each interview transcript was read and re-read, and thoughts were written down in the margin. Thereafter, the topics were clustered together and organised into major topics, unique topics and left-over topics. These topics were abbreviated (as codes) and the transcripts were re-read and the codes added next to the appropriate segments of the text. The most descriptive wording for the topics were found and turned into categories. The data material was grouped under each identified category (Creswell, 2009, p. 186). Categories and subcategories were identified and clustered. These categories and subcategories were compared to the analysis by an independent coder, and consensus was reached about these categories (Fouché \& Schurink, 2011, p. 413).

\section{Ethical considerations}

Three fundamental ethical principles guided this researcher: respect for persons, beneficence and justice (Brink et al., 2006, p. 31). The study was approved by the Medunsa Research Ethics Committee of the University of Limpopo (Medunsa campus) (Project number: MREC/H/47/2012:PG). Permission for the study was granted by the chief executive officer of the Gauteng hospital. Written informed consent was obtained from the participants by providing them with written and verbal information in their mother tongue. The healthcare provider and her personal assessment provided the researcher with information regarding the participants' mental health, i.e. that participants were in contact with reality and had the capacity to consent to the study. Confidentiality was ensured by interviewing participants in a private room, removing all names from the documentation and using codes instead (Bless, Higson-Smith, \& Kagee, 2006, p. 143). The participants were duly informed that they had the right to decide whether or not to participate in the study without the risk of penalty, and that they had the right to withdraw from the study at any time (Brink et al., 2006, p. 32).

The researcher believed that it was improbable that any physical or emotional harm would occur to the participants, and due to her training and skills as an advanced psychiatric nurse she felt she was able to conduct the interviews respectfully and sensitively. The participants were also monitored for any signs of distress (Brink et al., 2006, p. 33; Strydom, 2011, p. 115). The researcher had worked in this hospital in the female psychiatric ward and thus had experience in the care treatment and rehabilitation of mental healthcare users. Those who experienced emotional distress could be referred to the psychologist or social worker if required. However, this was not necessary for any of the ten participants. The participants benefited by having an opportunity to verbalise their experiences of parenting with a chronic mental illness in a safe environment.

\section{Trustworthiness}

The principles for trustworthiness, as described by Lincoln and Guba (1985, cited in Polit \& Beck, 2012), were applied. Measures of credibility, dependability, confirmability, transferability and authenticity were used to enhance the trustworthiness of this study as summarised in Table 1.

\section{Findings, literature control and discussion}

\subsection{Biographical information}

Six of the ten mothers were between 40 and 49 of age, three were between 30 and 39 years old, and one mother was between 20 and 29 years of age. Eight of the ten mothers were single, separated or divorced, and only one was employed. Four mothers were diagnosed with schizophrenia, four with bipolar disorder and two with major depressive disorder.

The two categories that emerged from the data reported on in this article relate to the challenges they experienced and their associated family support needs. The categories and subcategories are summarised in Table 2.

\subsection{Category 1: challenges for mothers with regard to caring for their children}

The challenges the mothers experienced related to insufficient financial resources, psychiatric symptoms, the effects of medication, a lack of alternative childcare when accessing services, fear and distress about separation, and stigmatisation. 
Table 1 - Measures to ensure trustworthiness.

\begin{tabular}{|c|c|}
\hline Criteria & Measure to ensure trustworthiness \\
\hline Credibility & $\begin{array}{l}\text { - Prolonged engagement and persistent } \\
\text { observation through building rapport, } \\
\text { interviewing for } 45-60 \text { min and } \\
\text { including } 10 \text { participants. } \\
\text { - Authority of the researcher as a psy- } \\
\text { chiatric nurse with } 15 \text { years' experience, } \\
\text { having a post-basic qualification in } \\
\text { psychiatric nursing and research } \\
\text { methodological preparation. } \\
\text { - Piloting the interview schedule. } \\
\text { - Peer reviewing by supervisors prepared } \\
\text { at master's and doctoral level. } \\
\text { - Audio-recording and verbatim tran- } \\
\text { scription of interviews. }\end{array}$ \\
\hline Transferability & $\begin{array}{l}\text { Providing dense description of the } \\
\text { research design and method, sample } \\
\text { and findings. }\end{array}$ \\
\hline Dependability & $\begin{array}{l}\text { - Using two persons to analyse the data } \\
\text { and reach consensus on the categories } \\
\text { and subcategories identified. } \\
\text { - Keeping an audit trail of documents } \\
\text { generated such as the consent letters, } \\
\text { audio-recordings, transcriptions and } \\
\text { translations, field notes, independent } \\
\text { coder notes and discussions, and a } \\
\text { report in the form of a dissertation. }\end{array}$ \\
\hline Confirmability & $\begin{array}{l}\text { - Developing an audit trail to ensure that } \\
\text { data sources could be traced and indi- } \\
\text { cating how constructs, themes and their } \\
\text { interpretations were derived. } \\
\text { - Identifying and setting aside any pre- } \\
\text { conceived beliefs and opinions that the } \\
\text { researcher might have had about } \\
\text { mothers living with a chronic mental } \\
\text { illness. } \\
\text { - Participating in peer discussions about } \\
\text { the findings in order to separate the re- } \\
\text { searcher's own experiences as a profes- } \\
\text { sional nurse from the findings of this } \\
\text { study }\end{array}$ \\
\hline Authenticity & $\begin{array}{l}\text { - Checking the researcher's understand- } \\
\text { ing of the data with the participants } \\
\text { during interviews by paraphrasing and } \\
\text { clarifying whether she had interpreted } \\
\text { what was said by the participants } \\
\text { correctly. } \\
\text { - Audio-recording and including verbatim } \\
\text { quotes to ensure that the voices of par- } \\
\text { ticipants were included. }\end{array}$ \\
\hline
\end{tabular}

\subsubsection{Insufficient financial resources}

The mothers described their challenges relating to insufficient financial resources to meet their own and their children's basic daily needs such as clothing and food. For the participants this challenge was compounded by the fact that they were not employed. One mother said: "I used to go with my children to town buying them beautiful clothes now I'm no longer doing that." Another said: "[It] is just that now I'm suffering I'm no longer able to buy beautiful clothes for my children and nice food like other children."
Table 2 - Categories and subcategories of parenting experiences of mothers living with a chronic mental illness.

\begin{tabular}{ll}
\hline CATEGORY & \multicolumn{1}{c}{ Subcategory } \\
\hline Category 1: Challenges for mothers with & - Insufficient financial \\
regard to caring for their children & resources \\
& - Psychiatric \\
& symptomatology \\
- Effects of medication & - Lack of alternative \\
& childcare when access- \\
& ing health services \\
- & Fear and distress about \\
& separation \\
- Stigmatisation & - Enhanced understand- \\
& ing of mental illness \\
& and treatment by \\
& mothers and their \\
Category 2: Family support needs & children \\
& Enhanced parenting \\
& skills \\
- Parent-friendly ar- & rangements for \\
& mothers who are \\
& hospitalised \\
\hline
\end{tabular}

Money was also necessary for them to go for follow-up visits and the mothers had to weigh up their priorities. Often, not having the funds to visit the hospital led to them postponing their follow-up visits. A participant explained,"Sometimes I don't have money to go for follow-up visits, and I will wait until I get my disability grant money."

Many of the mothers depended on their disability grants of R1260.00 per month and child support grants of R280.00 per month (South African Social Security Agency, 2012). Even those mothers who were young and could still be gainfully employed were unable to do so because of their mental illness. One mother said: "I want to try to find a job but I'm scared that I'm going to get sick while I'm working because I cannot handle stress and lose my job."

The mothers in this study said that the children's biological fathers did not support them financially. One participant had the following to say about this:

"I went to maintenance court so that he [the father] can support the children. He is supporting them but some months he doesn't and it becomes difficult for me to buy food for the children."

Another participant said: "My husband is not working, he is doing piece jobs [part-time employment] and I am also not working. I am getting my grant and [a grant] for my children, [these grants] [are the ones] that support us."

Various studies (Montgomery et al., 2006, p. 21; Seeman, 2008, p. 335) report that living with a mental illness increases the chance that a woman will live in poverty. Women with a serious mental illness suffer high rates of unemployment (Canadian Mental Health Association, n.d., para. 5). In addition, many women with a mental illness are single parents (Seeman, 2008, p. 335), so they do not have the support of 
a spouse's income. In this study, the lack of income influenced the mothers' ability to access health services. Diaz-Caneja and Johnson (2004, p. 477) too found financial resources to influence a mother's ability to access health services.

\subsubsection{Psychiatric symptomatology}

Mothers explained that their psychiatric symptoms, especially during acute episodes of mental illness, prevented them from caring for their children. One mother said: "I'm always tired. When I'm sitting down I feel like not standing again. I sit almost the whole day doing nothing. I don't know whether [it] is the medications."

Three mothers with a chronic mental illness acknowledged that they had thoughts of harming their children during an acute psychotic episode. One mother explained: "My main problem is that when I start getting sick, I become irritable and beat my children. Then they become afraid of me, but I love them." Another mother said: "I had a thought of killing her [child]. Then I put her on the floor, and couldn't understand why I had these thoughts."

These three mothers confirmed that, at the time of the interviews when they received treatment as outpatients, actions and thoughts of harming their children were no longer the case. The researcher, in her professional capacity, had a duty to report any potential or real harm to the children. However, this was not necessary as this information had already been known to the treating healthcare providers of these three women.

Diaz-Canja and Johnson (2004, p. 476) also found that the challenges related to psychiatric symptomatology and dealing with parenting and their own mental health needs impaired mothers' ability to parent effectively. In certain circumstances, psychiatric symptomatology and the mothers' inability to care pose a real risk of harm to their children, such as the risk for maltreatment or abuse reported by mothers in this study and in which case children required protection (Australian Infant Child Adolescent and Family Mental Health Association, 2004, p. 5). According to Montgomery et al. (2006, p. 24), mothers may have thoughts of hurting their children in an acute phase of mental illness, regardless of how much they love their children.

\subsubsection{Effects of medication}

The side-effects of their medication affected the mothers' parenting abilities. The mothers spoke of the side-effects of antipsychotic medication, such as fatigue and sedation. It prevented them from attending to personal grooming and appearance, from getting things done and from attending to the day-to-day needs of their children. They felt that medication slowed them down and reduced their concentration. One mother said: "At times I'm tired and don't have energy. I think [it] is the medication that make[s] me to feel tired and [I] don't have strength." Another mother also said: "I feel sleepy all the time." Yet another said: "Medication makes me [to] sleep a lot."

In order to deal with the side-effects, the mothers thought of stopping their medication. One mother said: "I took medication for a year only and stopped them because they made me feel sleepy, and I cannot cook for my children, nor wash their clothes, nor help them with their schoolwork."

In addition to the challenges experienced by the psychiatric symptoms themselves, the side-effects of medications further impacted on mothers and their parenting abilities (Diaz-Caneja \& Johnson, 2004, p. 476).

\subsubsection{Lack of alternative childcare when accessing health services}

Some mothers reported missing their follow-up healthcare appointments because there was no one to take care of their children. They explained that this and stopping their medication led to relapses for them. Although some mothers had support available from their relatives, others did not. One mother said: "Things that hurt me a lot are that I don't have somebody who would take care of my children when I'm admitted at the hospital or when I go for check-ups to collect my medication." Another one said: "My life is a mess because when I go to the hospital to collect my medication, my child has no one to look after her. Sometimes she goes with me to the hospital."

The practical challenge of not having adequate and readily available childcare impacted on the mothers' ability to access healthcare services. This challenge was also reported by DiazCaneja and Johnson (2004, p. 477) who found that financial resources and lack of alternative childcare arrangements influenced mothers' ability to access mental health services.

\subsubsection{Fear and distress about separation}

Participants explained their fear and distress about potential or actual separation from their children and the consequences of not being available for them.

Fear of custody loss was very prominent with many participants. One mother said: "I' $m$ the one who fears that he [father] might take them from me saying that I'm an unfit mother." Another stated the following:

"I was scared when I was admitted at the hospital that they would take my children from me. I don't want them to stay with somebody or be taken away from me... I don't feel good about my children being taken away from me; I want my children to stay with me. I'm their mother; I gave birth to them ... I don't want my children to grow without knowing that I'm their mother."

Those who had lost custody tended to describe this as a severe blow. One participant said: "They [healthcare providers] took the child from me and gave him to the social worker. My life is a mess because my child will no longer know that I'm his mother. He will call other people mommy."

Many mothers worried about not being good parents and not being available for their children. They expressed concerns about their children having to fulfil "parenting roles" on their behalf. Mothers also expressed guilt about not having time to spend with their children, especially during periods of hospitalisation. One said: "I am regretting because I didn't have time with my children." Another mother said: "This has impacted on my life because most of the time I'm admitted at the hospital because of stress. I leave my child with my first born child. I think it's too heavy for her [the older child]."

Another said: "When I relapse, he [child] sees me first and he will go to tell my mother at home and take me to the hospital."

Many women with a mental illness who have been hospitalised more than once and for extended periods experience grief and loss due to separation from their children (DiazCaneja \& Johnson, 2004, p. 477; Dipple et al., 2002, p. 339; 
Lagan et al., 2009, p. 54). This grief and loss may also be experienced by the children, not only due to the physical separation during hospitalisation, but also when the mother is physically present but emotionally absent due to her mental illness (Australian Infant Child Adolescent and Family Mental Health Association, 2004, p. 6).

\subsubsection{Stigmatisation}

The mothers experienced stigmatisation which affected their children as well. One mother said: "I don't want my children to go to them [neighbours] because they say I'm crazy." Another participant said:

"One day my child came from playing, crying. When I asked her what the problem was, she said other children refused to play with her. She said their mothers told them not to play with her [child] because her mother was crazy."

The stigmatisation experienced by mothers and their children in this study is a common theme in research of persons with mental illness and research related to parenting with mental illness (Australian Infant Child Adolescent and Family Mental Health Association, 2004, p. 6; Diaz-Caneja \& Johnson, 2004, p. 476, Jessop \& De Bondt, 2012, p. 53). Stigmatisation by those in the health system as well as in the larger community is also present. It is generally assumed that mothers with a mental illness are unfit parents and mothers have to prove that they are in fact able to parent (Dipple et al., 2002, p. 336). David et al. (2011, p. 146) add that stigmatisation and fear contribute to the "systematic neglect of parenting concerns" by mothers with a mental illness.

\subsection{Category 2: family support needs}

The mothers expressed their need for family support. They needed to better understand their mental illness and treatment, and their children also needed to better understand mental illness. They required assistance to enhance their parenting skills and parent-friendly arrangements when they were hospitalised.

One of the mothers in this study reported a need for support to cope with parenting: "I don't know what to do with these problems. They are too heavy for me."

\subsubsection{Enhanced understanding of mental illness and} treatment by mothers and their children

Mothers said that they and their children needed more information and a better understanding of mental illness and treatment. Mothers specifically mentioned that they needed a better understanding of mental illness, the nature of their symptoms, the severity of their illness, their treatment and their prognosis.

A mother reported that she did not know what her illness was - she was told that it was "bipolar". As one mother explained: "I want to know more about bipolar ... and' ... why I become irritable like this."

Another mother reported that a change of medication which she was not informed about rendered her unable to parent: "I want to know why they changed my medication because the medication given to me makes me feel tired." Another mother said: "I want to know when I will stop drinking medication because I was drinking them for 16 years."

In addition to needing a better understanding for themselves, mothers said that they needed their children too to have a better understanding of their mental illness. One mother said: "I want my children to know that if I'm unable to do the simplest day-to-day chores I used to do, they must know that I'm sick but I love them."

Seeman (2004, p. 167) agrees that mothers' behaviour, hospitalisation and treatment are not explained to the mothers or children. Cowling (2004, p. 88) states that health professionals should appreciate that mothers with a mental illness are parents first and that they should show that understanding by educating mothers about treatment. This education may potentially help the family members to cope better with the situation (Australian Infant Child Adolescent and Family Mental Health Association, 2004, p. 6). According to Maybery and Reupert (2009, p. 788), young people want to be involved in their parents' care. The findings of this study concur with those of Cowling (2004, p. 88) and Seeman (2004, p. 167), namely that children need to have their parents' mental illnesses explained to them and that this is often not the case. Diaz-Caneja and Johnson (2004, p. 479) suggest that more support, including home visitation, should be provided to the children of mothers with a mental illness.

\subsubsection{Enhanced parenting skills}

Mothers explained the difficulties with disciplining their children, implying that they needed to improve their parenting skills. Some mothers told stories of being disrespected by their children and expressed a need for someone to intervene. One mother said: "Children started not listening to me when I was talking to them." Another mother said: "I was frustrated about the behaviour of my child". One mother stated that: "They [children] say I'm crazy."

One of the mothers in this study reported that she was unable to discipline her children and that they did not listen to her when she talked. She said: "I wish there was someone, a man, who can talk to him about this issue ... because when I talk to him he doesn't listen. I think he is disrespecting me because I'm suffering from mental illness."

The importance of promoting parenting practices has been reported as preventative in nature, as it is possible that the parenting skills of a parent with a mental illness may be impaired (Craig, 2004, p. 925). As in this study, Diaz-Caneja and Johnson (2004, p. 473) found that mothers were concerned about disciplining their children and lacked confidence in this regard.

\subsubsection{Parent-friendly arrangements needed by mothers who} are hospitalised

Participants verbalised their concerns about their children during times when they were hospitalised and expressed a need for more parent-friendly arrangements for their children when they were hospitalised.

They were concerned about being separated from their children when hospitalised. One participant said: "When I'm admitted at the hospital I look around me and I ask myself that when I'm sleeping here where are my children?" Another said: "When I was admitted at the hospital I was thinking of my children, where 
are they? Who is taking care of them? Who is bathing and making food for them?"

Difficulties arose when mothers experienced a relapse and were admitted to hospital or when they went for follow-up treatment. One participant said: "If it was possible that when you are admitted at the hospital and your child doesn't have anybody to take care of him/her, they should allow us to sleep with them in the hospital until we are discharged."

A mother reported that she had wanted to go home to check on her children when admitted and to come back after doing so: "When I was admitted at the hospital I was asking doctors and nurses to go home to see my children. Then I will come back."

Another mother had eventually asked about arrangements that could be made to stay with her child at social welfare or to look for placement for her so that she could stay with her child there: "I want to know whether it is possible to look for placement for me so that I can take my child and stay with him. Alternatively is it possible for me to go and stay with him at the welfare?"

Hospitalisation and accessing health services have been described as challenging to mothers with a mental illness due to child care arrangements and difficulties arising in their relationships with their children as a result of hospitalisation (Diaz-Caneja \& Johnson, 2004, p. 477). Separation from their children may be very distressing and may contribute to the mother's current mental illness (Dipple et al., 2002, p. 340).

Cowling (2004, p. 354) states that mental health services are limited in considering and providing for the needs of mental healthcare users who are parents.

\section{Limitations}

Although the study provided a rich discussion of the parenting experiences of mothers with a chronic mental illness at a Gauteng hospital, there are some limitations that need mentioning. Firstly, the study only focused on the parenting experiences of mothers and excluded the perspectives of the whole family system. Secondly, the findings of the study cannot be generalised to all mothers with a chronic mental illness, as their experiences were their own unique experiences based on their unique parenting experiences within this context.

\section{Recommendations}

It is recommended that healthcare services provide adequate parenting support for mothers, and that more nursing research be conducted and nursing education be implemented in this regard.

\subsection{Recommendations for mental healthcare services}

Healthcare services should provide adequate support to mothers in their parenting roles and to their children, and should be able to protect children who may be at risk of harm (Thomson \& Fudge, 2005, p. vii).

A family-centred approach that would address all the challenges of mothers and their children should be followed (Seeman, 2008, p. 332). This requires holistic assessments and interventions with the families as units (Australian Infant
Child Adolescent and Family Mental Health Association, 2004, p. 7). The focus of these assessments and interventions should be on the mothers' parenting abilities (behavioural, cognitive and social skills), the home environment, social support networks and their children's welfare. Risk for neglect or harm of children should be assessed continuously (Ackerson, 2003, p. 190; Diaz-Caneja \& Johnson, 2004, p. 473; Lagan et al., 2009, p. 54). Moreover, specific questions pertaining to reproductive and parenting histories, challenges and needs should be included in assessment documents (David et al., 2011, p. 148).

To enforce the family-centred approach, policies that address the rights of mothers with a chronic mental illness as well as the rights of their children should be put into place (David et al., 2011, p. 149). In the in-patient setting, these policies should enable contact between mothers and children. This contact should, however, take place with consideration for the child and the therapeutic benefit for the parent, and should take place in a suitable and safe environment (North Hamptonshire National Health System Foundation Trust, 2012, p. 5).

In addition, parent support programmes for mothers with chronic mental illnesses that are contextually and culturally relevant and include existing social support networks and economic resources should be developed and implemented (Australian Infant Child Adolescent and Family Mental Health Association, 2004, p. 7; David et al., 2011, pp. 146-147).

\subsection{Recommendations for nursing research}

Replication of this study using a larger sample and widening the population to include the opinions of the families of mothers would lead to a better and more in-depth understanding of the experiences of mothers with a chronic mental illness as well as of their families, and could also assist in identifying family support needs. The experiences of fathers and children with a mental illness could also be included.

\subsection{Recommendations for nursing education}

Higher education institutions involved in the education and training of nurses should emphasise a holistic approach to the care of mothers with mental illness. Healthcare providers should receive training in parenting rights and be educated about the concerns of mothers with a serious mental illness (David et al., 2011, p. 148). Their training should include learning how to support mothers' parenting roles, how to protect children who are at risk for harm, client referral systems and ethical issues (Thomson \& Fudge, 2005, p. vii).

\section{Conclusion}

Mental healthcare providers should be aware that female mental healthcare users may also be mothers and that these mothers and their children have specific challenges and needs. These challenges and family support needs, such as financial constraints and lack of alternative childcare, impede mothers' abilities to access the very health services they need 
in order to maintain their level of functioning and parenting ability. Viewing mothers as "patients" rather than parents robs them of the holistic care they and their children require. A family-centred approach that supports both mothers and their children should be encouraged by establishing familycentred policies and procedures for women with chronic mental illnesses (Maybery \& Reupert, 2009, p. 790).

\section{Competing interest}

The authors declare that they have no financial or personal relationship(s) which may have inappropriately influenced them in writing the paper.

\section{Authors' contributions}

A.M.R. (University of Limpopo, Medunsa campus) was the master's degree candidate and primary researcher, and was involved in drafting the paper. Y.H. was the supervisor and was involved in the drafting, editing and final reviewing of the paper. M.M. was the co-supervisor and was involved in the final evaluation and editing of the paper.

\section{Acknowledgements}

We express our gratitude to the mothers who participated in the study, and all persons and institutions who granted permission for conducting this study. Thank you to the University Nursing Education South Africa (UNEDSA) for the scholarship awarded for this study and to Dr Annie Temane for acting as the independent coder for the study.

\section{R E F E R E N C E S}

Ackerson, B. J. (2003). Parents with serious and persistent mental illness: issues in assessment and services. Social Work, 48(2), 187-194.

American Psychiatric Association. (2013). Diagnostic and statistical manual of mental disorders (DSM5) (5th ed.) Retrieved from http://www.cnuckols.com.

Australian Infant Child Adolescent and Family Mental Health Association. (2004). Principles and actions for services and people working with children of parents with a mental illness. Stepney: Australian Infant Child Adolescent and Family Mental Health Association.

Beardslee, W. R., Wright, E. J., Gladstone, T. R. G., \& Forbes, P. (2007). Long-term effects from a randomized trial of two public health preventative interventions for parental depression. Journal of Family Psychology, 21(4), 703-713.

Bless, C., Higson-Smith, C., \& Kagee, A. (2006). Fundamentals of social research methods: An African perspective (4th ed.). Cape Town: Juta.

Brink, H., Van Der Walt, C., \& Van Rensburg, G. (2006). Fundamentals of research methodology for healthcare professionals (2nd ed.). Cape Town: Juta.
Burns, N., \& Grove, S. K. (2009). The practice of nursing research: Appraisal, synthesis and generation of evidence (6th ed.). Philadelphia: MO Saunders/Elsevier.

Canadian Mental Health Association. (n.d.). Mothers with mental illness. Retrieved from http://www.ontario.cmha.ca/women.asp.

Cowling, V. (2004). Models of service provision in three countries: Marlboro, New Haven, Sydney, Melbourne and Lewisham. In M. Gopfert, J. Webster, \& M. V. Seeman (Eds.), Parental psychiatric disorder: Distressed parents and their families (2nd ed.). (pp. 345-360). Cambridge: Cambridge University Press.

Craig, E. A. (2004). Parenting programs for women with mental illness who have young children: a review. Australian and New Zealand Journal of Psychiatry, 38(11-12), 923-928.

Creswell, J. W. (2009). Research design: Qualitative, quantitative, and mixed methods approaches (3rd ed.). London: Sage Publications.

David, D. H., Styron, T., \& Davidson, L. (2011). Supported parenting to meet the needs and concerns of mothers with severe mental illness. American Journal of Psychiatric Rehabilitation, 14(2), 137-153.

Diaz-Caneja, A., \& Johnson, S. (2004). The views and experiences of severely mentally ill mothers: a qualitative study. Social Psychiatry and Psychiatric Epidemiology, 39(6), 472-482. Retrieved from http://dx.doi.org/10.1007/s00127-004-0772-2.

Dipple, H., Smith, S., Andrews, H., \& Evans, B. (2002). The experience of motherhood in women with severe and enduring mental illness. Social Psychiatry and Psychiatric Epidemiology, 37(7), 336-340.

Doucet, S. A., Letourneau, N. L., \& Stoppard, J. M. (2010). Contemporary paradigms for research related to women's mental health. Health Care for Women International, 31(4), 296-312. Retrieved from http://dx.doi.org/10.1080/ 07399330903518509.

Eshel, N., Daelmans, B., de Mello, M., \& Martines, J. (2006). Responsive parenting: interventions and outcomes. Bulletin of the World Health Organization, 84(12), 991-998.

Falkov, A., \& Lindsey, C. (2011). Patients as parents: Addressing the needs, including the safety of children whose parents have mental illness. London: Royal College of Psychiatrists.

Fouché, C., \& Schurink, W. (2011). Qualitative research designs: interviewing. In A. de Vos, H. Strydom, C. Fouché, \& C. Delport (Eds.), Research at grass roots: For the social sciences and human service professionals (4th ed.). (pp. 307-327). Pretoria: Van Schaik.

Greeff, M. (2011). Information collection: interviewing. In A. de Vos, H. Strydom, C. Fouché, \& C. Delport (Eds.), Research at grass roots: For the social sciences and human service professionals (4th ed.). (pp. 341-375). Pretoria: Van Schaik.

Holloway, I., \& Wheeler, S. (2010). Qualitative research in nursing and healthcare (3rd ed.). West Sussex: Wiley-Blackwell.

Jessop, M. E., \& De Bondt, N. (2012). A consultation service for Adult Mental Health Service clients who are parents and their families. Advances in Mental Health, 10(2), 149-156.

Kahng, S. K., Oyserman, D., Bybee, D., \& Mowbray, C. (2008). Mothers with a serious mental illness: when symptoms decline does parenting improve? Journal of Family Psychology, 22(1), 162-166. Retrieved from http://dx.doi.org/10.37/08933200.22.1.162.

Lagan, M., Knights, K., Barton, J., \& Boyce, P. M. (2009). Advocacy for mothers with psychiatric illness: a clinical perspective. International Journal of Mental Health Nursing, 18(1), 53-61.

Maybery, D., \& Reupert, A. (2009). Parental mental illness: a review of barriers and issues for working with families and children. Journal of Psychiatric and Mental Health Nursing, 16(9), 784-791.

Maybery, D., Reupert, A., Patrick, K., Goodyear, M., \& Crase, L. (2009). Prevalence of parental mental illness in Australian families. Psychiatric Bulletin, 33, 22-26. 
Montgomery, P., Tompkins, C., Forchuk, C., \& French, S. (2006). Keeping close: mothering with mental illness. Journal of Advanced Nursing, 54(1), 20-28.

Morse, J. (2011). What is qualitative health research? In N. K. Denzin, \& Y. S. Lincoln (Eds.), The Sage handbook of qualitative health research (4th ed.). (pp. 401-414). Thousand Oaks, California: Sage.

Moultrie, A., \& Kleintjies, S. (2006). Women's mental health in South Africa. In P. Ijumba, \& A. Padarath (Eds.), The South African health review. Retrieved from http://www.hst.org.za/ uploads/files/chap21_06.pdf.

Nicholson, J., Geller, J. L., Fisher, W. H., \& Dion, G. L. (1993). State policies and programs that address the needs of mentally ill mothers in the public sector. Hospital and Community Psychiatry, 44(5), 484-489.

North Hamptonshire National Health System Foundation Trust. (2012). Policy for children visiting in-patient and residential units. North Hamptonshire National Health System Foundation Trust.

Oyserman, D., Mowbray, C. T., Meares, P. A., \& Firminger, K. B. (2000). Parenting among mothers with a serious mental illness. American Journal of Orthopsychiatry, 70(3), 296-313.

Polit, D. F., \& Beck, C. T. (2012). Nursing research: Generating and assessing evidence for nursing practice (9th ed.). Philadelphia: Lippincott Williams \& Wilkins.

Reupert, A., \& Maybery, D. (2011). Programmes for parents with a mental illness. Journal of Psychiatric and Mental Health Nursing, 18(3), 257-264.

Sadock, B. J., \& Sadock, V. A. (2007). Kaplan \&Sadock's synopsis of psychiatry: Behavioural science/clinical psychiatry (10th ed.). Philadelphia: Lippincott Williams \& Wilkins.
Seeman, M. V. (2004). Schizophrenia and motherhood. In M. Gopfert, J. Webster, \& M. V. Seeman (Eds.), Parental psychiatric disorder: Distressed parents and their families (2nd ed.). Cambridge: Cambridge University Press.

Seeman, M. V. (2008). Prevention inherent in services for women with schizophrenia. The Canadian Journal of Psychiatry, 53(5), 332-341.

South African Social Security Agency. (2012). You and your grants, 2021/2013, booklet. Pretoria: Government Printer.

Strydom, H. (2011). Ethical aspects of research in the social sciences and human service professions. In A. de Vos, H. Strydom, C. Fouché, \& C. Delport (Eds.), Research at grass roots: For the social sciences and human service (4th ed.). (p. 115). Pretoria: Van Schaik.

Thomson, J., \& Fudge, E. (2005). Adult mental health nurses' beliefs and practices when nursing clients who are parents of children under 18. Stepney: Australian Infant Child Adolescent and Family Mental Health Association.

University of Johannesburg, Department of Nursing Science. (2009). Theory for health promotion in nursing. Johannesburg: University of Johannesburg.

Ward, C., \& Wessels, I. (2013). Rising to the challenge: towards effective parenting programmes. In L. Berry, L. Biersteker, A. Dawes, L. Lake, \& C. Smith (Eds.), South African child gauge. Cape Town: Children's Institute, University of Cape Town.

World Health Organization. (2001). World health report 2001 Mental health: New understanding, new hope. Retrieved from http://www.who.int/whr/2001/en/whr01-en.pdf. 